\title{
Value of Rotation Thrombelastometry in Cardiac Surgical Patients with Normal Bleeding Risk-A Pilot Study
}

Stefan $P$ Wirtz, $M D^{1^{*}}\left(\mathbb{D}\right.$, Florian R Fritzsche, $M D, P H D, M P H^{2}$, Christoph Schmidt, $M D, P H D^{3}$, Benno von Bormann, $M D, P H D^{4}$, Gehard Brodner, $M D, P H D^{5}$ and Elmar Berendes, $M D, P H D^{6}$

${ }^{1}$ Department of Anesthesiology, Intensive Care and Pain Management, Helios Hospital Bad Saarow, Germany ${ }^{2} P A T H O$ diagnostics $A G$, Geltenwilenstrasse, St. Gallen, Switzerland

${ }^{3}$ Department of Anesthesiology and Intensive Care, University Hospital Münster, Germany

${ }^{4}$ Faculty of Medicine, Suranaree University, Nakhon Ratchasima, Thailand

${ }^{5}$ Department of Anesthesia, Intensive Care and Pain Management, Fachklinik Hornheide, Münster, Germany

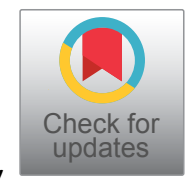

${ }^{6}$ Department of Anesthesiology and Intensive Care, Helios Hospital Krefeld, Germany

\begin{abstract}
Study objective: The ROTEM ${ }^{\circledR}$ Whole Blood Haemostasis Analyser has been introduced for point-of-care monitoring using computerized rotation thrombelastometry, an enhancement of thrombelastography ${ }^{\circledR}$. This study aimed to investigate the clinical relevance of the ROTEM ${ }^{\circledR}$ device in patients undergoing routine cardiac surgery.

Design: Prospective, double-blinded clinical study.

Setting: University hospital, operating room, intensive care unit.

Patients: Forty-two cardiac surgical patients with normal bleeding risk.

Interventions: Routine cardiac surgical procedures with cardiopulmonary bypass.

Measurements: In addition to clinical data assessment, ROTEM ${ }^{\circledR}$-measurements were performed intra- and postoperatively. Standard ROTEM ${ }^{\circledast}$-tests comprised three different assays, i.e. INTEM: Intrinsic system-activation, EXTEM: Extrinsic system-activation, and HEPTEM: INTEM + heparinase.

Main results: All ROTEM $^{\circledR}$-variables showed the typical impairment of coagulation after cardiopulmonary bypass, such as impaired clot formation and stability. Independent samples t-tests demonstrated that there were no differences in blood loss and transfusions 2 and 8 hours postoperatively in patients with low and high ROTEM ${ }^{\circledR}$-values. Multivariate logistic regression analyses revealed a significant effect only of the duration of cardiopulmonary bypass on postoperative transfusion requirements. ROTEM ${ }^{\circledR}$-parameters, the total amount of administered fluids, and type of surgery were not associated with postoperative allogeneic transfusions and blood loss.

Conclusions: Although thrombelastometry with the ROTEM ${ }^{\circledR}$-device reflects the perioperative alterations in coagulation, the parameter changes to be expected in routine procedures with normal bleeding risk patients are of only limited predictive value in respect to postoperative blood loss and transfusion requirements. Therefore, thrombelastometry with ROTEM $^{\circledR}$ is not mandatory.
\end{abstract}

\section{Keywords}

Thrombelastography, Postoperative hemorrhage, Blood coagulation disorders, Normal bleeding risk, Cardiopulmonary bypass, Point-of-care systems

\section{Introduction}

Several factors contribute to the perioperative impairment of the coagulation system after open-heart surgery, e.g. dilutional coagulopathy (because of infusions and priming fluids), platelet dysfunction, activated coagulation and fibrinolysis, inflammation, and therapeutic heparinization. In many centers strategies have been established to decrease both the risk of bleeding and the inflammatory response following cardiopulmonary bypass (CPB) [1], by using antifibrinolytics, even in patients undergoing routine surgery.

In the past, several studies tried to uncover variables being useful a) To predict the individual risk of postoperative blood loss and transfusion requirements associated with cardiac surgery [2-6], and b) To improve patients' safety by 
Citation: Wirtz SP, Fritzsche FR, Schmidt C, et al. (2020) Value of Rotation Thrombelastometry in Cardiac Surgical Patients with Normal Bleeding Risk-A Pilot Study. J Clin Anesth Pain Manag 4(2):136-142

minimizing exposure to allogeneic blood products and by preventing bleeding-related emergencies (e.g. cardiac tamponade, rethoracotomy). In contrast to commonly available tests that mostly assess singular aspects of the hemostatic system, thrombelastography ${ }^{\circledR}\left(\mathrm{TEG}^{\circledR}\right)$ allows determining the whole process of clot formation and dissolution. Also, it helps to determine the principle mechanisms of platelet function, platelet-fibrinogen interactions, and fibrinolysis. Therefore, $\mathrm{TEG}^{\circledR}$ is currently used in different clinical settings [7].

However, results of studies using TEG ${ }^{\circledR}$ to estimate postoperative blood loss are incongruous. Whereas TEG $^{\circledR}$ failed to predict postoperative blood loss in some studies $[5,8,9]$, it was a helpful adjunct to hemostatic therapy in others. In this context, $\mathrm{TEG}^{\circledR}$-based transfusion algorithm regimes have resulted in decreased blood loss and reduction of transfusion requirements $[6,8,10-15]$. These conflicting reports on the usefulness of TEG $^{\circledR}$ in $\mathrm{CPB}$-surgery may partially be related to technical issues of the standard TEG ${ }^{\circledR}$.

Currently, modifications of standard TEG ${ }^{\circledR}$ have been introduced into clinical practice. In this regard, Yamakage and co-workers have reported a more rapid assessment of fibrinolysis by celite-activation [16]. Another modification with in vitro application of heparinase allows measurement of $\mathrm{TEG}^{\circledR}$-parameters, even under full heparinization during CPB [17].

The computerized ROTEM ${ }^{\circledR}$ Whole Blood Haemostasis Analyser (formerly by Pentapharm GmbH Diagnostic Division, Munich, Germany) provides results in approximately 10-15 minutes by adding specific activators. Problems of the standard $\mathrm{TEG}^{\circledR}$ in terms of reduced transportability and the high susceptibility to external vibrations or movements are eliminated by a ball bearing, limiting all possible movement to rotation [18]. This device allows the assessment of the intrinsic and the extrinsic system separately as well as the effects of heparin and fibrinolysis. Cammerer and co-workers recently reported promising results in cardiac surgical patients with different bleeding risks [19]. However, it remains unclear whether the ROTEM ${ }^{\circledR}$ device is of use in routine cardiac surgical patients with normal bleeding risk.

The present study was conducted to address two specific issues concerning the clinical use of rotation thrombelastometry: 1) Is thrombelastometry able to reflect the impairment of the hemostatic system resulting from uncomplicated $C P B$ ? and 2) Do coagulation abnormalities detected by the ROTEM ${ }^{\circledR}$ predict the risk of intraoperative blood loss and need for allogeneic transfusion?

\section{Material and Methods}

Approval of the local Ethics Committee and written informed consent of each patient were obtained. This study conforms to the ethical standards as set out in the Declaration of Helsinki. Forty-two consecutive patients undergoing routine open heart surgery as scheduled on the daily operation plan were investigated in this prospective clinical study.

Exclusion criteria for enrollment were: Age < 18 years, offpump techniques, expected bypass time below 30 minutes, any medication impacting on the hemostatic system (such as any dose of heparin administered $<6$ hours before induction of anesthesia, anti-platelet agents 5 days before surgery, etc.), and abnormalities in preoperative coagulation profiles (activated thromboplastin and prothrombin time, and platelet count). Therefore, the study population comprised only cardiac surgical patients with normal bleeding risk.

Anaesthesiological and surgical management were standardized for all patients. Anticoagulation was accomplished by $400 \mathrm{IU} \mathrm{kg}^{-1}$ heparin as an initial dose and additional heparin to maintain an activated clotting time using kaolin as the activating agent (ACT; ACT $\|{ }^{\circledR}$ Medtronic, Minneapolis, MN) > 400 seconds. All procedures were performed using a moderately hypothermic bypass-technique (approximately $34.5^{\circ} \mathrm{C}$ ). After separation from bypass, heparin was neutralized by $300 \mathrm{IU}$ $\mathrm{kg}^{-1}$ protamine (ICN Pharmaceuticals Germany GmbH, Frankfurt, Germany). The blood remaining in the extracorporeal circuit after the termination of CPB was washed and concentrated by an autotransfusion device (CellSaver $5^{\circledR}$, Haemonetics Corp., Braintree, MA) and then retransfused. Fluid management was performed by the attending anesthesiologists according to institutional standards and clinical requirements mainly guided by central venous pressure, systemic arterial blood pressure, and transesophageal echocardiography.

Five different time points with expected changes of the coagulation system were chosen for measurements: $\mathrm{T} 1$ = Baseline after induction of general anesthesia; T2 = After separation from $\mathrm{CPB}$ and preceding protamine infusion; $\mathrm{T} 3$ = After protamine administration and before retransfusion of salvaged blood; $\mathrm{T} 4=$ at the end of the procedure; $\mathrm{T} 5=\mathrm{Two}$ hours after surgery on the ICU. Blood samples were drawn under sterile conditions from the radial artery catheter together with blood for routine tests.

Modified thrombelastographic-measurements were performed using the ROTEM ${ }^{\circledR}$ Whole Blood Haemostasis Analyser (formerly by Pentapharm GmbH Diagnostic Division, Munich, Germany) as described previously [18-20]. Standard testing with the ROTEM $^{\circledR}$-device comprised three routine assays: 1) INTEM: Thrombelastometry with activation of the intrinsic system (20 $\mu$ l of partial thromboplastin for factors XII, XI, IX, VIII, X, V, II, and I and platelets; In-TEM ${ }^{\circledR}$, Pentapharm GmbH Diagnostic Division, Munich, Germany), 2) EXTEM: Thrombelastometry with activation of the extrinsic system ( $20 \mu \mathrm{l}$ of tissue thromboplastin for factors VII, X, V, II, and I and platelets; Ex-TEM ${ }^{\circledR}$, Pentapharm GmbH Diagnostic Division, Munich, Germany), 3) HEPTEM: INTEM with $2 \mathrm{U}$ ml-1 of heparinase to determine heparin-effects when compared

*Corresponding author: Stefan P Wirtz, MD, Department of Anesthesiology, Intensive Care and Pain Management, Helios Hospital Bad Saarow, Pieskower Straße 33, D-15526 Bad Saarow, Germany, Tel: +49-33631-7-3581, Fax: +49-33631-7-2548

Accepted: November 24, 2020

Published online: November 26, 2020

Citation: Wirtz SP, Fritzsche FR, Schmidt C, et al. (2020) Value of Rotation Thrombelastometry in Cardiac Surgical Patients with Normal Bleeding Risk-A Pilot Study. J Clin Anesth Pain Manag 4(2):136-142 
Citation: Wirtz SP, Fritzsche FR, Schmidt C, et al. (2020) Value of Rotation Thrombelastometry in Cardiac Surgical Patients with Normal Bleeding Risk-A Pilot Study. J Clin Anesth Pain Manag 4(2):136-142

to INTEM; Hep-TEM ${ }^{\circledR}$, Pentapharm GmbH Diagnostic Division, Munich, Germany). The following variables were analyzed for each of the three tests at each time point: 1) Coagulation time (CT; time from the start of measurement until the beginning of clot formation reflecting initial coagulation activation. The CT becomes prolonged in the presence of clotting factor deficiencies, inhibitors, anticoagulants, thrombocytopenia) equivalent to standard TEG ${ }^{\circledR}$ 's reaction time $r$; 2 ) Clot formation time (CFT; time from the beginning of clot formation until an amplitude of $20 \mathrm{~mm}$ is reached reflecting the increase of elastic shear modulus in the sample, i.e. the rapidity of clot structure formation. The CFT becomes abnormal in the presence of clotting factor deficiencies, platelet dysfunction, thrombocytopenia, hypofibrinogenaemia) equivalent to standard TEG ${ }^{\circledR}$ 's coagulation time k; 3) Clot firmness (A-value) 5, 10 , and 15 minutes ( $A 5, A 10, A 15)$ after $C T$, and 4) Maximum clot firmness (MCF), equivalent to standard $T E G^{\circledR \prime}$ 's maximum amplitude MA to assess fibrinogen concentration, factor VIII- and XIII-activity, and platelet number and function [21] (A-values and MCF are also decreased in the presence of a pathologically prolonged clotting time as a result of severe factor deficiencies or heparin therapy); and 5) Maximum lysis in percent of MCF, if applicable. Before neutralization of heparin, ROTEM $^{\circledR}$-testing is merely possible adding heparinase to the probe. Therefore, only HEPTEM was analyzed at T2. To exclude experimental bias, clinicians involved in the care of the study patients were unaware of the study design.

ACT was measured at T1, T2, and T5; thromboplastin time, and prothrombin time at T5. At each time point, a red blood cell and platelet count were performed. Red blood cells were transfused intraoperatively, when hematocrit was $<18 \%$ during $\mathrm{CPB}$ and $<25 \%$ after weaning from CPB. As transfusions were one major end-point of this study, strict clinical adherence to this transfusion algorithm was assured. Postoperative blood loss was determined by measuring blood in the drain tubes two and eight hours after admission to the ICU.

Also, we determined the number of transfused blood products during the intervention and postoperatively, the type and duration of the surgical procedure, bypass time, biometrical patient characteristics, preoperative medication, and infused fluids.

\section{Statistical analysis}

All data were analyzed using SPSS for Windows version 11.0.1 (SPSS Inc., Chicago, IL). Descriptive statistics comprised mean values \pm and standard deviations, and ranges. Changes of values between each time point vs. baseline have been assessed by Kruskal-Wallis one way analysis of variance on ranks with Tukey post-hoc-test.

Independent samples t-tests with blood loss and the number of allogeneic transfusions after eight hours as dependent variables were used to assess differences between patients with low and high ROTEM ${ }^{\circledR}$-values (ROTEM ${ }^{\circledR}$-values above the median against values below the median). ROTEM ${ }^{\circledR}$-parameters should differentiate significantly between patients with high and low postoperative blood loss. A total sample size of
42 patients ( 21 patients with ROTEM $^{\circledR}$-values above and 21 patients with ROTEM $^{\circledR}$-values below the median) would be suitable to detect a significant effect size $f=0.8$ with a statistical power of $1-\beta=0.8$ and a significance level of $\alpha=0.05$.

Correlations between each ROTEM $^{\circledR}$-variable and blood loss and allogeneic transfusions, respectively, two and eight hours after the end of the procedures were determined using the Pearson moment product formula. Also, multivariate logistic regression analysis was used to evaluate the association of ROTEM ${ }^{\circledR}$-parameters 1 ) With allogeneic transfusions $(<1$ or $\geq 2$ units of packed red blood cells) and 2) With blood loss ( $<300$ or $\geq 500 \mathrm{ml}$ ) after eight hours corrected for the following confounding factors that might independently be associated with these two variables: Type of surgery (coronary artery bypass grafting vs. all other routine procedures), duration of CPB and total amount of administered fluids (during and within the first 2 hours after the procedure).

Table 1: Patient characteristics and data from the perioperative period. Values are expressed as $n$ or mean \pm standard deviation, unless otherwise indicated.

\begin{tabular}{|c|c|c|}
\hline Age (years) & & $65 \pm 9$ \\
\hline Sex (n female/ n male) & & $14 / 28$ \\
\hline Height (cm) & & $172 \pm 7$ \\
\hline Weight (kg) & & $77 \pm 13$ \\
\hline \multirow[t]{7}{*}{ Preoperative medication ( $\mathrm{n}$ ) } & $\beta$-blocker & 34 \\
\hline & $\mathrm{Ca}^{2+}$ antagonists & 34 \\
\hline & Nitrates & 30 \\
\hline & Glycosides & 5 \\
\hline & ACE inhibitors & 23 \\
\hline & AT1 antagonists & 9 \\
\hline & Diuretics & 14 \\
\hline \multirow[t]{4}{*}{ Procedures (n) } & CABG & 30 \\
\hline & AVR & 7 \\
\hline & MVR & 2 \\
\hline & other & 3 \\
\hline Duration of surgery (min) & & $177 \pm 45$ \\
\hline Duration of CPB (min) & & $86 \pm 31$ \\
\hline \multirow[t]{2}{*}{ Blood loss (ml) } & 2 hrs. postop. & $\begin{array}{l}142 \pm 76 \\
\text { (range 20-360) }\end{array}$ \\
\hline & $8 \mathrm{hrs}$. postop. & $\begin{array}{l}318 \pm 154 \\
\text { (range 120-705) }\end{array}$ \\
\hline \multirow[t]{2}{*}{ Transfusions intraoperative } & patients (n) & 12 \\
\hline & PRBC (units) & $2.0 \pm 0.4$ \\
\hline \multirow{3}{*}{$\begin{array}{l}\text { Transfusions } 2 \text { hrs. } \\
\text { postoperative }\end{array}$} & patients $(n)$ & 15 \\
\hline & PRBC (units) & $1.7 \pm 0.6$ \\
\hline & $\begin{array}{l}\text { no transfusion } \\
\text { at all }\end{array}$ & 17 \\
\hline
\end{tabular}

CABG: Coronary artery bypass grafting; AVR: Aortic valve replacement; MVR: Mitral valve replacement; CPB: Cardiopulmonary bypass; PRBC: Packed red blood cells. 


\section{Results}

\section{Patient characteristics}

Patient characteristics and data from the perioperative period are shown in Table 1. Apart from packed red blood cells, no other allogeneic blood products were transfused in any patient included in the study.

\section{Time course of variables}

All ROTEM ${ }^{\circledR}$-parameters at each time point differed significantly from baseline values except CT in INTEM two hours after surgery (Figure 1, Figure 2 and Figure 3). In this study, platelets decreased over time: Baseline: $199 \pm 55 \mathrm{nl}^{-1}$; after CPB: $115 \pm 43 \mathrm{nl}^{-1}$; two hours after admission to the ICU: $141 \pm$ $41 \mathrm{nl}^{-1}$ with statistically significant differences versus baseline at each time point.
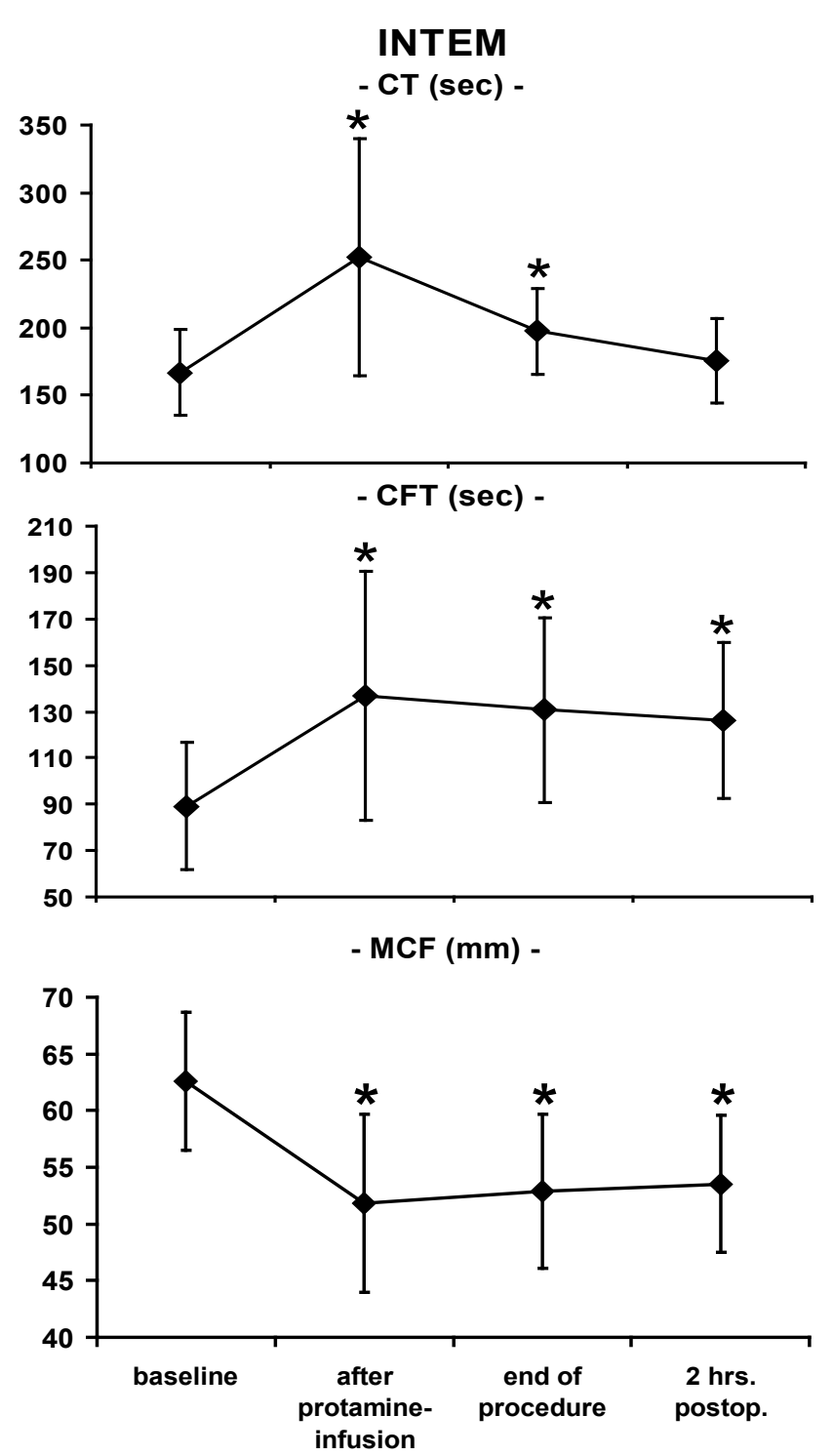

Figure 1: The course of coagulation time (CT), clot formation time (CFT), and maximum clot firmness (MCF) in intrinsically activated ROTEM $^{\circledR}$ (INTEM). Values are expressed as mean \pm SD. $*=$ Statistically significant difference versus baseline $(p<0.05)$.
Whereas partial thromboplastin time was increased two hours after surgery, (56 $\pm 14 \mathrm{sec}$., normal 24-36 sec.), prothrombin time remained almost within the normal range (67 $\pm 14 \%$, normal $70-130 \%$ ). Compared to baseline values, ACT was significantly prolonged intraoperatively but not two hours after the end of the procedure (baseline: $135 \pm 13 \mathrm{sec}$.; T2: $481 \pm 82$ sec.; T5: $131 \pm 15 \mathrm{sec}$.).

\section{Analysis of associations with blood loss and transfusion requirements}

No differences for all ROTEM ${ }^{\circledR}$-parameters were found

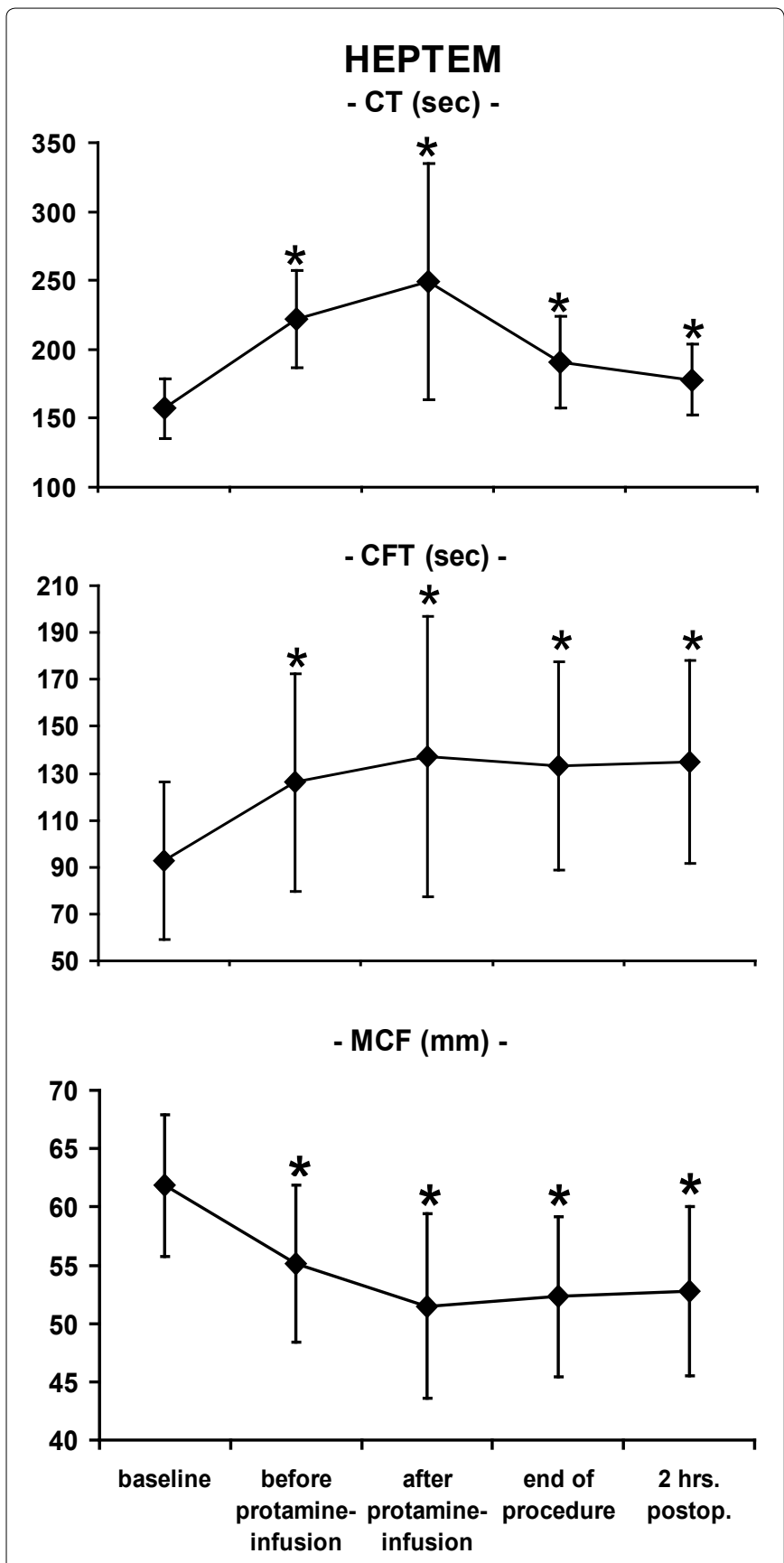

Figure 2: The course of coagulation time (CT), clot formation time (CFT), and maximum clot firmness (MCF) in intrinsically activated ROTEM $^{\circledR}$ with heparinase (HEPTEM). Values are expressed as mean \pm SD. ${ }^{*}=$ Statistically significant difference versus baseline $(p<0.05)$. 

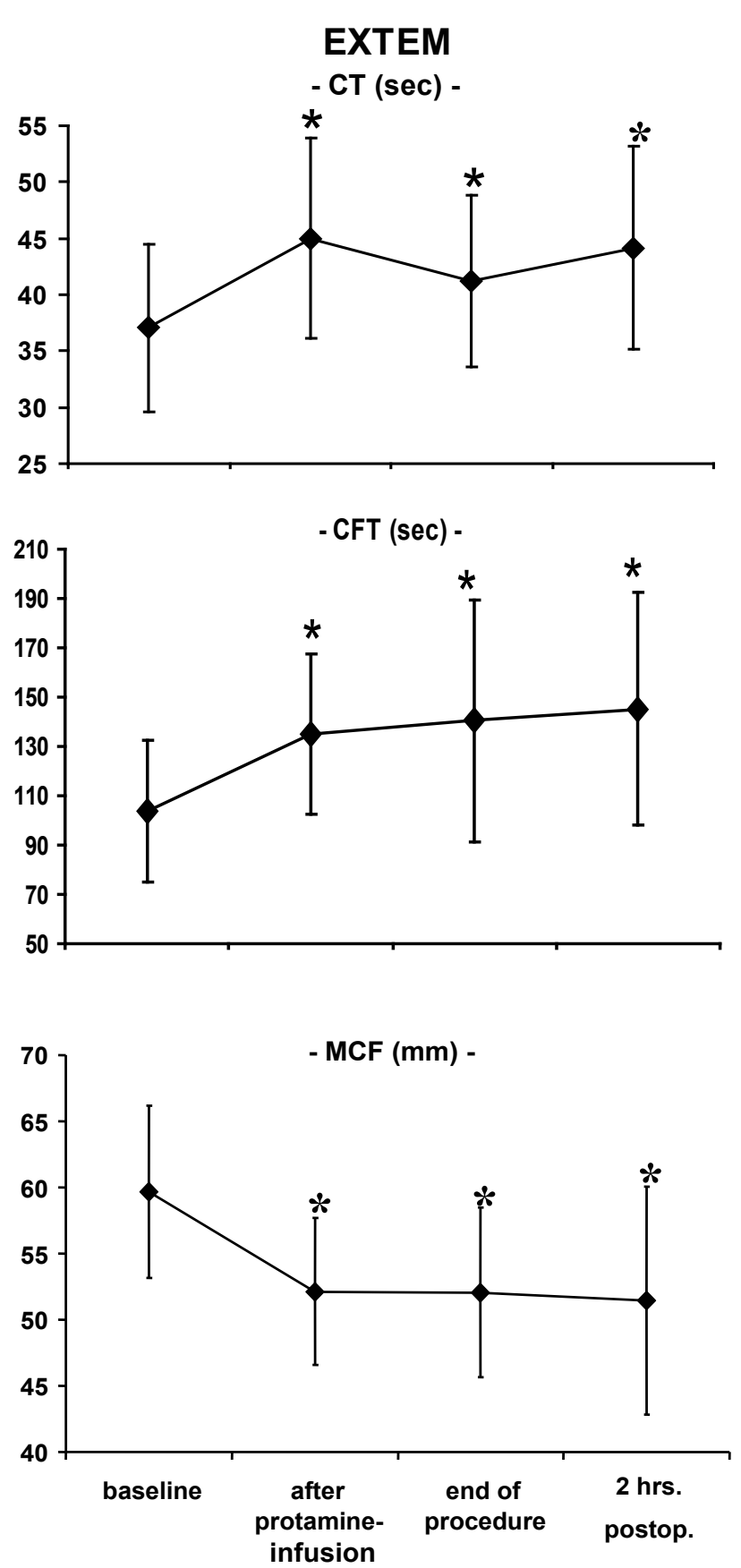

Figure 3: The course of coagulation time (CT), clot formation time (CFT), and maximum clot firmness (MCF) in extrinsically activated ROTEM ${ }^{\circledast}$ (EXTEM). Values are expressed as mean \pm SD. $*=$ Statistically significant difference versus baseline $(p<0.05)$.

comparing blood loss and transfusions in both patients with lower and higher values than the median at all time points (exemplary time points presented in Table 2).

Assessment of the amount of red blood cell transfusions revealed that CT with HEPTEM at T5 showed the highest degree of association of all ROTEM ${ }^{\circledR}$ variables with transfusion requirements during the first eight hours after the end of the procedure $(r=0.383 ; p=0.012)$. All other ROTEM $^{\circledR}$ variables did not correlate significantly with the number of transfused packed red blood cells using both multivariate logistic regression and Pearson correlation analyses $(-0.3>r<0.3)$. Also, the duration of CPB was significantly associated with transfusion requirements, as well.

Analysis with blood loss as the dependent variable indicated that CFT $(r=0.44 ; p=0.004)$ and MCF $(r=-0.44 ; p=0.004)$ with EXTEM at baseline showed the strongest association of all ROTEM ${ }^{\circledR}$ variables to blood loss eight hours postoperatively. All other variables were not significantly associated with blood loss $(-0.4>r<0.4)$ even after correction for confounding factors.

\section{Subgroup analysis}

In six of the 42 patients, at least one of the ROTEM ${ }^{\circledR}$-values (MCF, CT, CFT) were consistently pathologic (greater respectively smaller than mean values \pm standard deviation of the study population) throughout the entire study period. However, no patient experienced increased blood loss or other clinical problems (mean blood loss of those six patients: $128 \mathrm{ml}$ after two hours and $303 \mathrm{ml}$ after eight hours).

Eight patients with increased probability of fibrinolysis were identified by ROTEM $^{\circledR}$-measurements. The mean blood loss in these patients was $152 \mathrm{ml}$ after two hours and $348 \mathrm{ml}$ after eight hours, and therewith not elevated compared to the other patients.

\section{Discussion}

This study assessed the clinical relevance of modified $\mathrm{TEG}^{\circledR}\left(\mathrm{ROTEM}^{\circledR}\right)$ in routine cardiac surgery. The major finding was that ROTEM ${ }^{\circledR}$-parameters were not associated with increased blood loss and transfusion requirements, but reflected perioperative impairment of the coagulation system.

Bedside monitoring of the complex coagulation system in the setting of cardiovascular surgery is desirable but difficult. TEG ${ }^{\circledR}$ is a global coagulation test that can reflect the entire process of forming and dissolving a thrombus. The clinical usefulness of standard TEG ${ }^{\circledR}$, however, is limited by the duration of the tests and its susceptibility to mechanical interferences [9]. Although numerous studies investigated the feasibility to use $T E G^{\circledR}$ in clinical practice, lacking validation of the derived variables is one of the major criticisms against routine use in general [22].

This study was carried out to investigate the clinical value of a new computerized modified multi-channel thrombelastometry system in routine cardiac surgery. Specifically, we aimed to focus on normal patients not treated with any drugs potentially influencing the coagulation system before surgery.

To evaluate the clinical usefulness of the ROTEM ${ }^{\circledR}$-system in this particular setting, two aspects are of major interest. First, the ability of the device to detect coagulopathies, and second to use this information to predict postoperative blood loss. In the present study, significantly impaired values (vs. baseline measurements) occurred in each ROTEM $^{\circledR}$-variable at almost any time point, reflecting typical and well-documented changes of the coagulation system during open-heart procedures using CPB [3]. The fact that there were no differences of CT in INTEM values as compared to baseline implies 
Citation: Wirtz SP, Fritzsche FR, Schmidt C, et al. (2020) Value of Rotation Thrombelastometry in Cardiac Surgical Patients with Normal Bleeding Risk-A Pilot Study. J Clin Anesth Pain Manag 4(2):136-142

Table 2: Association of ROTEM ${ }^{\circledR}$ variables with allogeneic packed red blood cell (PRBC) transfusions and blood loss ( 8 hours postoperatively): As representative examples, $p$-values of independent samples t-tests at baseline and 2 hours after surgery are presented. PRBC transfusions and blood loss 8 hours postoperatively are dependent variables to assess differences between patients with ROTEM ${ }^{\circledR}$-values below and above the median.

\begin{tabular}{|l|l|l|l|l|}
\hline $\begin{array}{l}\text { ROTEM } \\
\text { variable }\end{array}$ & $\begin{array}{l}\text { PRBC } \\
8 \text { hrs. postop. }\end{array}$ & $\begin{array}{l}\text { Blood loss } \\
8 \text { hrs. postop. }\end{array}$ & $\begin{array}{l}\text { PRBC } \\
8 \text { hrs. postop. }\end{array}$ & $\begin{array}{l}\text { Blood loss } \\
8 \text { hrs. postop. }\end{array}$ \\
\hline & Baseline & & hours postop. & p-value \\
\hline & p-value & p-value & p-value & 0.405 \\
\hline CT INTEM & 0.062 & 0.459 & 0.315 & 0.996 \\
\hline CFT INTEM & 0.504 & 0.494 & 0.504 & 0.31 \\
\hline MCF INTEM & 0.064 & 0.746 & 0.091 & 0.407 \\
\hline CT HEPTEM & 0.179 & 0.957 & 0.223 & 0.451 \\
\hline CFT HEPTEM & 0.256 & 0.328 & 0.178 & 0.098 \\
\hline MCF HEPTEM & 0.134 & 0.776 & 0.064 & 0.746 \\
\hline CT EXTEM & 0.38 & 0.844 & 0.425 & 0.439 \\
\hline CFT EXTEM & 0.739 & 0.213 & 0.315 & 0.513 \\
\hline MCF EXTEM & 0.256 & 0.105 & 0.315 & \\
\hline
\end{tabular}

that protamine restored initial coagulation activation. All other ROTEM $^{\circledR}$-variables were still different two hours post-surgery indicating perioperative impairment of the hemostatic system. The changes in ROTEM ${ }^{\circledR}$-parameters were associated with a significant reduction in platelet count, pathologically extended partial thromboplastin and prothrombin time.

The most important result of the present study for clinical practice is the absence of meaningful correlations of the amount of postoperative allogeneic blood transfusions and blood loss with intra- and early postoperative ROTEM $^{\circledR}$-variables. Notably, we used different analytic techniques for a detailed evaluation of this issue. First, we chose the median of the ROTEM ${ }^{\circledR}$-values as a cut point to compare high versus low values concerning blood loss and need for blood transfusion. Second, Pearson correlations and, finally, multivariate logistic regression analyses (to correct for other factors that might influence these dependent variables) were performed to assess the association of different ROTEM $^{\circledR}$-variables with transfusions and postoperative blood loss. Except for some singular ROTEM $^{\circledR}$-parameters, these associations had to be declined.

Analysis of subpopulations revealed that some patients had pathological ROTEM ${ }^{\circledR}$-measurements. These findings are in accordance with other studies reporting $10-46 \%$ of patients with pathologic $\mathrm{TEG}^{\circledR}$-tests without bleeding $[6,9,10,13]$.

Previous study results of $\mathrm{TEG}^{\circledR}$ in cardiac surgery are conflicting. Some authors found a significant correlation of TEG ${ }^{\circledR}$-parameters and increased postoperative blood loss, emphasizing the predictive value of maximal amplitude $[6,10,13,23]$. Spiess and colleagues reported a reduction in postoperative bleeding complications and the rate of rethoracotomies with a $\mathrm{TEG}^{\circledR}$-based blood management program in cardiac surgery [11]. Likewise, Shore-Lesserson, et al. demonstrated that the need for fresh frozen plasma and platelets was significantly reduced using celite-activated $\mathrm{TEG}^{\circledR}$ [12]. On the contrary, $\mathrm{TEG}^{\circledR}$ failed to correlate with postoperative blood loss in other studies $[5,8,9]$.

In conclusion, the results of our pilot study suggest that the variables determined with the ROTEM ${ }^{\circledR}$ Whole Blood Haemostasis Analyser reflect the impairment of the hemostatic system secondary to perioperative influences. Future large-scale studies are needed to confirm the notion that the ROTEM $^{\circledR}$ device does not help to predict the individual risk of hemorrhage and allogeneic blood transfusion requirements following routine cardiac surgery in patients with normal bleeding risk. Since this study was not designed to investigate the usefulness of ROTEM ${ }^{\circledR}$ in high-risk patients and those with high blood loss, further evaluation in this specific population is warranted.

The ROTEM $^{\circledR}$-device (former name: roTEG Coagulation Analyzer ${ }^{\circledR}$ ) used in this study has been provided by the former manufacturer (Nobis Labordiagnostica, Endingen, Germany) intended for testing purposes in our institution for no charge during the trial period, the assays for the ROTEM ${ }^{\circledR}$-device and all other material and equipment has been supplied by the authors' institution.

\section{References}

1. Laupacis A, Fergusson D (1997) Drugs to minimize perioperative blood loss in cardiac surgery: Meta-analyses using perioperative blood transfusion as the outcome. The International Study of Perioperative Transfusion (ISPOT) Investigators. Anesth Analg 85: 1258-1267.

2. Gravlee GP, Arora S, Lavender SW, et al. (1994) Predictive value of blood clotting tests in cardiac surgical patients. Ann Thorac Surg 58: 216-221.

3. Gelb AB, Roth RI, Levin J, et al. (1996) Changes in blood coagulation during and following cardiopulmonary bypass: Lack of correlation with clinical bleeding. Am J Clin Pathol 106: 87-99.

4. Liu G, McNicol PL, McCall PR, et al. (2000) Prediction of the mediastinal drainage after coronary artery bypass surgery. Anaesth Intensive Care 28: 420-426. 
5. Cherng YG, Chao A, Shih RL, et al. (1998) Preoperative evaluation and postoperative prediction of hemostatic function with thromboelastography in patients undergoing redo cardiac surgery. Acta Anaesthesiol Sin 36: 179-186.

6. Spiess BD, Tuman KJ, McCarthy RJ, et al. (1987) Thromboelastography as an indicator of post-cardiopulmonary bypass coagulopathies. J Clin Monit 3: 25-30.

7. Caprini JA, Traverso Cl, Arcelus JI (1995) Perspectives on thromboelastography. Semin Thromb Hemost 4: 91-93.

8. Dorman BH, Spinale FG, Bailey MK, et al. (1993) Identification of patients at risk for excessive blood loss during coronary artery bypass surgery: Thromboelastograph versus coagulation screen. Anesth Analg 76: 694-700.

9. Wang J, Lin C, Hung W, et al. (1992) Thromboelastogram fails to predict postoperative hemorrhage in cardiac patients. Ann Thorac Surg 53: 435-439.

10. Tuman KJ, Spiess BD, McCarthy RJ, et al. (1989) Comparison of viscoelastic measures of coagulation after cardiopulmonary bypass. Anesth Analg 69: 69-75.

11. Spiess BD, Gillies BS, Chandler W, et al. (1995) Changes in transfusion therapy and reexploration rate after institution of a blood management program in cardiac surgical patients. J Cardiothorac Vasc Anesth 9: 168-173.

12. Shore-Lesserson L, Manspeizer HE, DePerio M, et al. (1999) Thromboelastography-guided transfusion algorithm reduces transfusions in complex cardiac surgery. Anesth Analg 88: 312319.

13. Essell JH, Martin TJ, Salinas J, et al. (1993) Comparison of thromboelastography to bleeding time and standard coagulation tests in patients after cardiopulmonary bypass. J Cardiothorac Vasc Anesth 7: 410-415.

14. Royston D, von Kier S (2001) Reduced haemostatic factor transfusion using heparinase-modified thrombelastography during cardiopulmonary bypass. Br J Anaesth 86: 575-578.

15. Koster A, Kukucka M, Fischer T, et al. (2001) Evaluation of post-cardiopulmonary bypass coagulation disorders by differential diagnosis with a multichannel modified thromboelastogram: A pilot investigation. J Extra Corpor Technol 33: 153-158.

16. Yamakage $M$, Tsujiguchi N, Kohro S, et al. (1998) The usefulness of celite-activated thromboelastography for evaluation of fibrinolysis. Can J Anaesth 45: 993-996.

17. Tuman KJ, McCarthy RJ, Djuric M, et al. (1994) Evaluation of coagulation during cardiopulmonary bypass with a heparinase-modified thromboelastographic assay. J Cardiothorac Vasc Anesth 8: 144-149.

18. Calatzis A, Haas S, Gödje O, et al. (2000) Thrombelastographic coagulation monitoring during cardiovascular surgery with the ROTEG coagulation analyzer. In: Pifarré R, Management of bleeding in cardiovascular surgery. (edn) Hanley \& Belfus Inc., Philadelphia, USA, 215-226.

19. Cammerer U, Dietrich W, Rampf T, et al. (2003) The predictive value of modified computerized thromboelastography and platelet function analysis for postoperative blood loss in routine cardiac surgery. Anesth Analg 96: 51-57.

20. Boldt J, Haisch G, Suttner S, et al. (2002) Are lactated Ringer's solution and normal saline solution equal with regard to coagulation? Anesth Analg 94: 378-384.

21. Kettner SC, Panzer OP, Kozek SA, et al. (1999) Use of abciximab-modified thrombelastography in patients undergoing cardiac surgery. Anesth Analg 89: 580-584.

22. Samama CM (2001) Thromboelastography: The next step. Anesth Analg 92: 563-564.

23. Ereth MH, Nuttall GA, Klindworth JT, et al. (1997) Does the platelet-activated clotting test (HemoSTATUS(R)) predict blood loss and platelet dysfunction associated with cardiopulmonary bypass? Anesth Analg 85: 259-264.

DOI: $10.36959 / 377 / 345$

Copyright: (c) 2020 Wirtz SP, et al. This is an open-access article distributed under the terms of the Creative Commons Attribution License, which permits unrestricted use, distribution, and reproduction in any medium, provided the original author and source are credited. 